\title{
A Study on the Approaches to Culture Introduction in English Textbooks
}

\author{
$\operatorname{Lin} \mathrm{Zu}$ \\ School of Foreign Language, North China Electric Power University \\ Tel: 86-312-318-8265Ｅ-mail: zulin3188@163.com \\ Zheqiong Kong \\ School of Foreign Language, North China Electric Power University \\ Mailbox 336, No. 689 Huadian Road, Baoding 071003, Hebei, China \\ Tel: 86-312-754-2668Ｅ-mail: kongzq666@yahoo.com.cn
}

\begin{abstract}
Language is embedded in society and culture, and for that matter, learning a foreign language involves learning its culture. This paper is concerned with the inseparability of culture and language in foreign language teaching, arguing that culture introduction is an effective way to promote students' cultural awareness and language proficiency. Foreign language textbooks are major channels for culture introduction. Therefore, this study attempts to analyze one set of English textbooks for Chinese secondary school students, and hence reveals the approaches to culture introduction in English textbooks.
\end{abstract}

Keywords: Culture introduction, English textbooks, Approaches, Direct introduction, Indirect introduction

\section{Introduction}

Linguists, especially language teachers and educators, are among the first to realize the importance of including host culture into foreign language curriculum and the impossibility of foreign language acquisition without relevant cultural understanding. Unfortunately, as some studies have shown, this does not necessarily lead to the practice of combining the two in language teaching classroom. The scarcity of authoritative, systematic and scientific culture materials and the irrationality of English textbook design have become, to some extent, barriers to the development of the English culture teaching. This study aims to probe into the main approaches to culture introduction in foreign language textbooks through a systematic analysis of one set of English textbooks entitled Learning English.

\section{Language and Culture}

\subsection{Defining Culture}

Culture is so broad in its scope that "there is not one aspect of human life that is not touched and altered by culture." (Hall, 1977, p.14) Till now linguists have had many kinds of definitions about culture; each has its own focus in one particular aspect, ranging from all-encompassing concepts like "it is everything" to some narrowly-viewed concepts like "it is opera or ballet".

It is believed that Sir Edward B. Tylor gave the first definition of culture. He defines culture as "That complex whole which includes knowledge, belief, art, morals, law, custom, and any other capabilities and habits acquired by man as a member of society."(Cited in Yue 1999, p.112) This concept of culture is all-embracing, and includes the behavioral ("custom"), the creative-material ("art"), the institutional ("moral" and "law"), and the cognitive ("knowledge" and "belief"). Robertson (Cited in Deng, 1989) says that "culture consists of all the shared products of human society." Samovar et al (2000, p.36) define culture as "the deposit of knowledge, experience, beliefs, values, actions, attitudes, meanings, hierarchies, religion, notions of time, roles, spatial relations, concepts of the universe, and artifacts acquired by a group of people in the course of generations through individual and group striving". This is a descriptive definition that tries to cover everything about culture. It has even included the aspect of nonverbal communication.

We can see from the above-mentioned definitions, although they are given from different angles, that culture is shared, learned, transmitted, integrated with ways of life, deep in beliefs, values, and social norms. Besides, culture is dynamic and subject to change.

\subsection{Inseparability of Culture and Language}

Some people say that language is the mirror of culture, in the sense that people can see a culture through its language. Others compare language and culture to an iceberg: the visible part is language, with a small part of culture; the greater 
part, lying hidden beneath the surface, is the invisible aspect of culture. Brown (2001, p.165) describes the relation of the two as follows: "A language is a part of a culture and a culture is a part of a language; the two are intricately interwoven so that one can not separate the two without losing the significance of either language or culture." In one word, culture and language are inseparable.

Through the following three metaphors, a new understanding of language and culture can be conveyed (Jiang, 2000).

From a philosophical view:
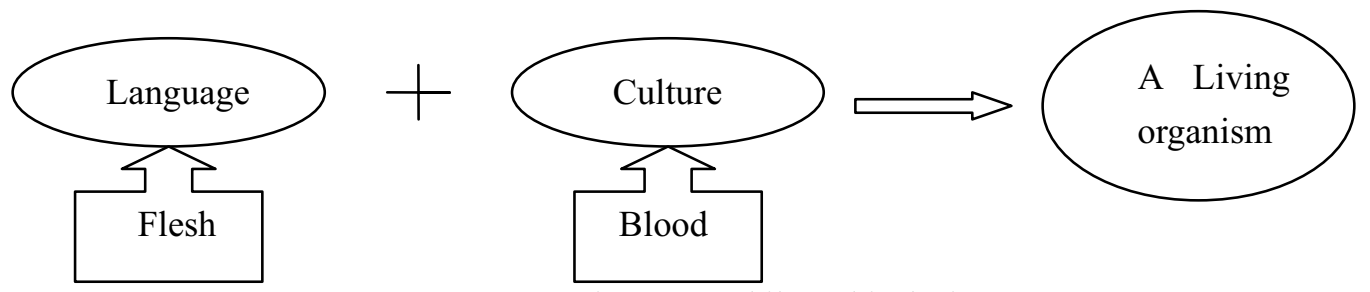

Figure 2-1 Philosophical View

Language and culture makes a living organism; language is fresh, and culture is blood. Without culture, language would be dead; without language, culture would have no shape.

From a communicative view:
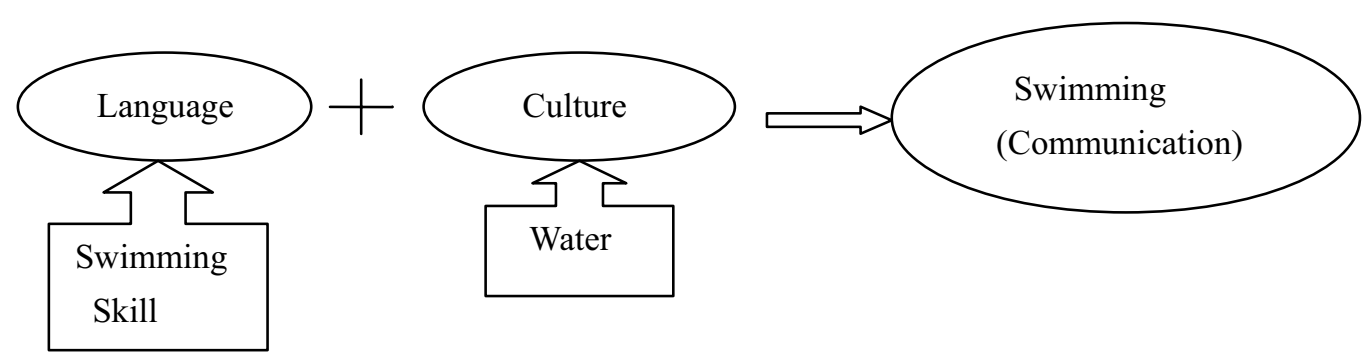

Figure 2-2 Communicative View

If communication is considered as swimming, language is the swimming skill, and culture is water. Without language, communication would remain to a very limited degree (in very shallow water); without culture, there would be no communication at all.

From a pragmatic view:
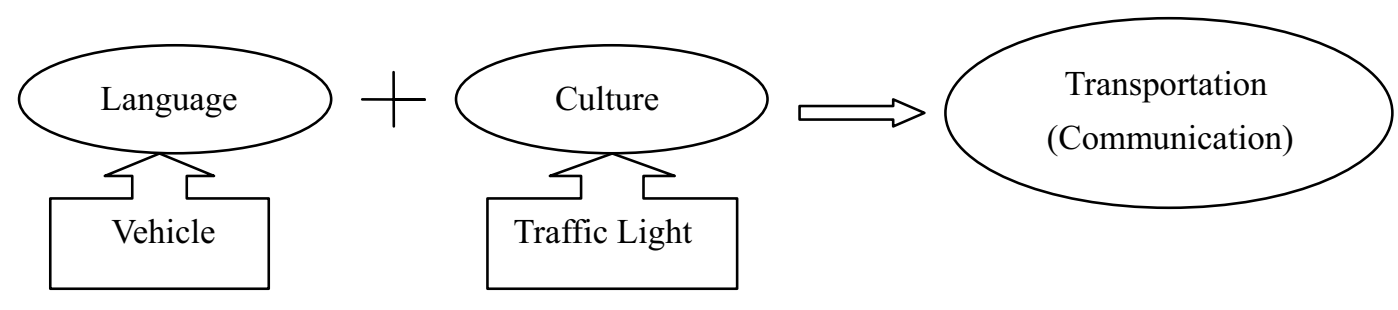

Figure 2-3 Pragmatic view

Communication is the transportation, language is the vehicle and culture is traffic light. Language makes communication easier and faster; culture regulates, sometimes promotes and sometimes hinders communication.

Culture and communication are inseparable because culture not only dictates who talks to whom, about what, and how the communication proceeds, it also helps to determine how people encode messages, the meanings they have for messages, and the conditions and circumstances under which various messages may or may not be sent, noticed, or interpreted. Culture is the foundation of communication.

\subsection{Culture in Foreign Language Teaching}

Due to the inseparability of language and culture, it is necessary to incorporate culture into the language teaching process. In her book Context and Culture in language Teaching, Kramsch (1993) states that cultural awareness and the learning of a second culture can only aid the attaining of second language proficiency. She also indicates that the teaching of culture implicitly or explicitly permeates the teaching of social interaction, and the spoken and the written language. In her view, second and foreign language learners necessarily become learners of the second culture because a 
language cannot be learned without an understanding of the cultural context in which it is used since "culture is not an independent aspect of language learning or teaching, it is a feature of language, it is always in the background, right from day one, ready to unsettle the good language learners' proficiency when they expect it least, making evident the limitations of their hard-won communicative competence, challenging their ability to make sense of the world around them." (Kramsch, 1993, p.1)

However, as we know, culture covers so many aspects that it is impossible to teach everything in limited classroom. Therefore, it is necessary to decide what and how to introduce and to what extent should culture be introduced in accordance with the students' current level of language proficiency.

\section{Approaches to Culture Introduction in English Textbooks}

Despite the fact that the majority of the language teachers and learners recognize the important role that culture plays in foreign language teaching and learning, we are still in dire need of cultural materials that could provide a comprehensive picture of culture knowledge required to conduct appropriately in cross-cultural communication. Since textbooks serve as a guide for language teachers in language education, it is of vital importance that textbooks provide a systematic and comprehensive cultural perspective for both the teachers and learners. In this regards, it is essential that textbook compilers take culture introduction into consideratrion by means of integrating culture into the English textbooks. In the hope of finding out the approaches to culture introduction in English textbooks, we will have a thorough analysis of one set of English textbooks entitled Learning English.

\subsection{Cultural Characteristics of Learning English}

Compared with the English textbooks more than one decade ago - the Junior English for China, the current one Learning English have definitely made a great breakthrough owing to its sufficient provision of cultural elements. There are the following six cultural features that are noticeable throughout the textbooks.

(1) Presentation of a wider range of cultural topics

This set of textbooks deals with topics of various kinds. Each unit centers on one particular topic. Most of these topics are concerned with the western cultures, or at least a reflection of them, which are certain to be of interest to learners. They include everyday life, leisure, family relationships, social customs, hot issues of contemporary society, etc. Whilst being primarily designed for language teaching, these topics are also informative, challenging, amusing, exciting and occasionally provocative. They can provide opportunities for expanding students' experience in general. Moreover, students may learn better when they are not only concentrating on learning the target language, but also knowing about the target culture.

(2) The variety of culturally-conditioned activities involved

The various activities or tasks in each lesson provide a great deal of opportunities for students to become more aware of the conventional behavior patterns in the target culture. They include pair-work, group discussion, role-play, interviewing, researching and so on. In the process of conducting these activities, students are actually learning to appreciate the way English people behave. Meanwhile, they may come up with their own creative way of coping with various circumstances.

(3) A truthful presentation of home culture and target culture.

In Learning English, we not only find target culture materials, but also home culture and international target culture materials. As an English learner, one will inevitably be involved in two or more different cultures. Therefore, one of the goals of language teaching is to train culturally double-directional learners who know about both their native culture and the target one, rather than to train totally native-like behavior imitators who cast their eyes solely on the target culture. Besides, it is our responsibility to introduce home culture to the target language people and vice versa. Consequently, it is of necessity that we incorporate both the home culture and the target culture materials into the English textbooks in the hope that we understand both cultures better. Learning English provides us with such an opportunity. It not only includes topics about western cultures, such as the various western holidays, their way of life, but also topics about Chinese culture.

\section{(4) A reflection of popular cultures}

Nowadays, with the popularization of computer and Internet, more and more people begin to use E-mail as a substitute for ordinary letters. Taking full advantage of this, Learning English presented most of its texts in the form of e-mails. Besides, it also discusses hot issues of the world today, like that of environmental protection, extinction of wild animals, the world population, etc. This can provide students with the opportunities to have a better understanding of the present society and keep up with the ever changing world.

(5) A focus on everyday life

Most of the topics in Learning English deal with different aspects of everyday life which would be of interest to 
teenagers. Thus, from time to time, students can ascertain the differences and similarities between their lifestyle and that of the target language people. This will, consciously or unconsciously, cultivate their awareness of the existence of potential contradictions and conflicts between the two cultures and build up a picture of life in the target community.

(6) Adoption of authentic pictures

The presentation of numerous authentic pictures, especially of good-quality visuals, is one of the remarkable features throughout the textbooks. Pictures are always visual, vivid, impressive and easy to understand; they can leave a deep impression on students and can thus promote and even reinforce their learning process. Moreover, the authentic pictures illustrated in the textbooks are a truthful reflection of some aspects of western and Chinese culture. They are a good way of informing, stimulating and enriching students' experience.

\subsection{Main Approaches to Culture Introduction in Learning English}

Since there are so many cultural elements included in this set of textbooks, we would better focus our attention on them in order that we could find out the approaches to culture introduction in these textbooks. According to our observation, there are mainly two approaches to the introduction of culture, that is, the direct and indirect introduction. The two approaches are then further divided into several subcategories.

\subsubsection{Direct Introduction}

By direct introduction, we mean that the textbooks provide students with materials concerning the cultural aspects of the language in a clear and unambiguous manner in the form of cultural knowledge, such as ways of greeting and farewell, ways of addressing, etc. It enables students to obtain cultural knowledge from the contents of textbooks in a direct way.

\subsubsection{Words Accompanied by Pictures}

To a large extent, understanding cultural diversity is also built on interpreting the denotative and connotative meaning of words. Therefore, a better understanding of word meaning can lead to a better understanding of cultural differences. However, as we know, in English, there are a lot of culture-loaded words and idioms that can hardly find their equivalents in Chinese. The textbooks tend to lead the students astray by giving wrong equivalents in which the English words and their supposed equivalents in fact refer to different things. For example, the English word "dragon" and its Chinese counterpart "long" are quite different both in image and connotation. More often than not, the English explanations will make the students more confused. In this case, a picture or photograph beside the English words not only saves us a lot of trouble but may also be pleasing to both the eye and the mind.

In Learning English, we can find the large amount of pictures alongside the English words. They not only facilitate the memorization of new words, but also enable students to use them in appropriate situations. With the help of pictures, students can know exactly what a donut is like, which color is blond, what a grocery store is like, etc.

\subsubsection{Situational Dialogues}

In the process of teaching situational dialogues, students are not only repeating and memorizing the sentence, but also understanding the explanation behind the conversation, i.e. the values and beliefs underlying it. This is well justified by the following conversation:

-Li Ming: I like your skirt.

-Jenny: Thanks! (Student Book 1, Lesson 13)

Was Jenny's reply immodest, as it seemed to some of the Chinese? Absolutely not! In English-speaking countries, praise is to be accepted, generally with a remark like "thank you." It is assumed that compliment is sincere, that the praise is for some not unworthy achievement or thing. Therefore, there should be no show of false humility, no pretended modesty. To Chinese, however, the customary reply to a compliment would be to claim that one is not worthy of the praise, that what one has done is hardly enough, or that success was more a matter of luck or some other circumstances. Acceptance of a compliment would imply conceit or lack of manners. Through the presentation of this small dialogue, students can perceive the "hidden" rules of conversation under their teacher's guidance and will thus be able to behave appropriately when faced with the same or similar situation.

In addition to that, culture knowledge can also be channeled into the content of the dialogues. Look at the following dialogue:

Li Ming: I like porridge for breakfast. Would you like some porridge?

Jenny: No, thanks! I like cereal for breakfast.

Li Ming: Cereal? What's cereal?

Jenny: In Canada we eat cereal for breakfast. I put milk and sugar on it. Would you like some? 
Li Ming: Yes. Mmmm ... It's delicious! (Student Book 1, Lesson 28)

From the above dialogue, students are able to distinguish the different dietary habits between English-speaking countries and China.

\subsection{3 Texts Depicting Cultural Events}

Texts are major carrier of culture knowledge. To some extent, they can convey comparatively greater amount of cultural information than words and dialogues. By virtue of texts, various cultural events such as holidays, historical events and geography can be illustrated. Besides, they can also reflect some aspects of culture, whether it be target culture or native culture. In Learning English, a lot of cultural information is conveyed through texts. Take the Student Book 4 as an example:

Lesson 34 is an introduction of railways which provides a great deal of facts about railways. For instance, who invented the steam engine? Who invented railways? And when did the passenger railway open?

Lesson 42 deals with e-mail instructions which inform students of how to get started, how to send e-mails and how to receive e-mails.

Lesson 46 talks about the two western holidays, i.e. Mother's Day and Father's Day. It presents the students with their respective history and the ways people celebrate them.

Lesson 49 to lesson 51 is concerned with geography. They provide students a lot about the world with its populations, oceans, deserts, rivers and so on.

\subsubsection{Cultural Notes}

The adoption of cultural notes in the English textbooks is a preferable way of introducing culture, especially in situations which might otherwise make students confused or even at a loss. However, this does not mean that we should provide as much cultural information as possible. We should take students' level of proficiency and time into consideration. This set of textbooks present the students with the appropriate amount of notes required to facilitate the understanding of texts. Most of them are concise, easy to understand, and presented in a humorous way.

For instance, in Lesson 6 of the Student Book 1, the given explanation of "Mrs." is like this: "I am married, so you can call me 'Mrs.' Liu. My husband is 'Mr.' Liu. My daughter is 'Miss' Liu." In this way, the usage of "Mrs., Mr., and Miss" is made quite clear. Other examples are as follows:

What's hot chocolate? It's a drink. It has hot milk, sugar and chocolate in it. It's so good! (Student Book 3, Lesson 29)

Do you know hockey? It's a sport. In Canada, everyone likes hockey. (Student Book 3, Lesson 29)

- The United Nations is a place where the countries of the world meet.

- I still don't understand! What do you mean by "United Nations"?

- Well, "united" means "together." The meaning of "nation" is "country."

- Oh! Now I understand. (Student Book 3, Lesson 42)

However, the direct approach has its limitations: though students have an overall knowledge of English culture, they are still in lack of real and actual communication. Communicative competence, if any, will be very limited with this kind of information provided directly by the textbooks.

\subsubsection{Indirect Introduction}

By indirect introduction, we mean that culture is presented in an implicit way, not in the form of cultural knowledge. Apart from the explicit cultural knowledge that is explainable and learnable through direct introduction, there are also some hidden and implicit aspect of culture, i.e. the values, attitudes and world outlooks that are vital to the understanding of a language. This set of textbooks approach these aspects of culture in two different ways, that is, cognitive approach and behavioral and affective approach.

\subsubsection{Cognitive Approach}

Cognitive approach here means the mental process in which students learn to think or to do things by virtue of the target language. The various tasks in these textbooks meant to introduce culture via cognitive approach. Some typical examples are as follows:

Task 1: Writing something about home culture

Irfan has learned a lot about China. Think of some things he may not know about your hometown. Write a letter to Irfan about them. (Student Book 3, Lesson 14)

Write an e-mail to describe a Chinese festival. When is it? How is it celebrated? How did it begin? (Student Book 3, Lesson 24) 
Task 2: Writing thank-you letter

Suppose it's your birthday today. You get many presents from your friends. Your parents have a party for you at home. Write a thank-you note/card/letter to thank your parents and friends. (Student Book 3, Lesson 23)

Task 3: Making contrast and comparison

Are hobbies the same or different in China and Canada?

First, study Canadian hobbies, using your Student Book and Activity Book/Reader.

Next, think of some hobbies in China. Do Canadian and Chinese people enjoy some of the same hobbies? Are some hobbies different in China and in Canada? Write down your ideas in a chart. (Student Book 3, Lesson 51)

Task 4: Searching for cultural information

People in different countries celebrate festivals in different ways. Try to find out more about festivals around the world. Discuss one or more of them with a partner, then exchange your ideas with another pair. (Student Book 3, Lesson 20)

Task 5: Cultural quizzes

Cultural quizzes are a preferable way for testing students' mastery of certain cultural knowledge. By quizzes, students can further consolidate their knowledge and learn something new to them as well. For example, after students have learned something about English-speaking countries, they are expected to do the following task:

A student stands in front of the class. He is thinking of a country. Ask him some questions. Guess the name of the country. (Student Book 1, Lesson 64)

Task 6: Discussion

Talk with a partner about these questions:

What do you think of the idea of April Fool's Day?

Have you ever played a trick on somebody? Share a trick with your partner.

What do you think "white lie" means? (Student Book 4, Lesson 22)

Task 7: Brainstorming

Before learning the text about Europe, two questions are presented to the students as warm-up exercises: What do you know about Europe? Make a list of the countries you know in Europe. (Student Book 4, Lesson 54)

By accomplishing the various tasks on one's own, students could check what they have learnt and find out things that they have missed and improve their language proficiency by noticing gaps in their own ability to explain. Besides, these tasks can stimulate students' interest of learning and knowing more about cultural knowledge.

\subsubsection{Behavioral and Affective Approach}

There are various kinds of activities assigned to students in Learning English. These activities can facilitate the learners to perceive the differences between cultures and thus provide learners with opportunities to adjust themselves to those differences. While conducting the various activities, students are actually learning to behave in a "new" situation and to empathize with the target language community, which is a process of testing how well the learners understand the language functions and the internal system of the foreign culture. It is hoped that students can work out the reasons for behavior or some abstract rules from observable behavior by themselves or under the guidance of the teachers. Some of these activities require a lot of knowledge and spontaneous reaction. Therefore, learners need sufficient information and exercises to get used to the western style of learning and the English way of expressing their opinions with the teachers' guidance. These activities include role-play, song-singing, experimentation and the like.

Activity 1: Role-play

(1) Planning a birthday party

It's Li Ming's birthday soon! Make a plan for his birthday party. What things do you need? Where will the party be? Who will come to the party? Who will bring the birthday cake? Share you plan with the rest of the class. (Student Book 3, Lesson 17)

(2) Asking the way

Act out a play with a partner. One of you is looking for a bookshop, theatre or museum, but you don't know the way. The other is a policeman who offers to help. Try using these expressions: Do you know the way to ? Go (direction) and turn . (Student Book 3, Lesson 30)

(3) Making telephone calls

Make up a dialogue with a partner. Act out a phone call between two friends. One is in China; the other is in the U.S. Try to use the expressions you learned in this lesson. (Student Book 3, Lesson 41) 
(4) Dealing with dogs

What do you think Mike's father and mother would do when Brandy ate the hamburgers? In a group of three, act out this scene. Who in your group will be Brandy? (Student Book 4, Lesson 18)

While acting out these scenes, students should put in the shoes of the western people. Take (4) as an example, for the majority of the people in Western countries, dogs are good companions or even faithfully friends. Unlike the Chinese, they seldom beat them or scold them. So students are expected to take this point into account while acting the play.

Activity 2: Song-singing

Songs can create a delightful atmosphere for both the learners and the teachers. In this sense, they can promote students' motivation of learning. In addition to that, by emerging themselves to songs, students can have a better understanding of what the song meant to convey. In lesson 60 of Student Book 3, there is a song like this:

Be confident in yourself,

Be proud of who you are,

Strive to be the best you can be!

We're unique -

You are you and I am me!

Be yourself and celebrate

How no one is quite like you!

Be yourself and celebrate -

You are special through and through!

There is an emphasis on and high praise of individuality between the lines. The advocate of individuality is quite common in most of the western countries, especially among young people. An awareness of this will certainly lead to students' better understanding of their peers in the target culture.

Although indirect introduction is a preferable way of fostering students' communicative competence, it is often prone to be neglected by both the teachers and students. Often times, they might fail to perceive what the textbook compiler have intended to convey. Another point is that, this approach requires the teacher to be possessed with high inter-cultural communicative competence. While students are fulfilling certain task, teachers should pay particular attention to their performance and give constructive suggestions for further improvement. In other words, both the teachers and students are required to reflect on their performance before they move on to the next part of lesson.

\section{Conclusion}

This paper, by discussing the relationship between language and culture, has contended that language and culture are closely associated and that channeling Western culture into English language curriculum is both important and necessary. Only if culture were integrated in language teaching, the whole teaching process would be complete. The direct and indirect introduction of culture in English textbooks could certainly make cultural learning and teaching manageable for both teachers and students and is therefore, a preferable way of introducing culture in English textbooks.

\section{References}

Brown, H. D. (2001). Principles of language learning and teaching. Beijing: Foreign Language Teaching and Research Press.

Deng, Yanchang, \& Liu, Runqing. (1989). Language and culture. Beijing: Foreign Language Teaching and Research Press.

Hall, E. T. (1977). Beyond culture. New York: Anchor Doubleday.

Jiang, W. T. (2000). The relationship between culture and language. EFT Journal, 54.

Kramsch, C. (1993). Context and culture in language teaching. Shanghai: Shanghai Foreign Language Education Press.

Luo, Changpei. (1950). Language and Culture. Beijing: Beijing Press.

Samovar, L. A., \& Porter, R. E., Stefani, L. A. (2000). Communication between cultures. Beijing: Foreign Language Teaching and Research Press.

Yue, Meiyun. (1994). Applied linguistics. Nanjing: Nanjing University Press. 